\title{
Meaningful stakeholder participation in marine spatial planning with offshore energy
}

\author{
Katherine L. Yates
}

School of Environment and Life Science, University of Salford Manchester, Salford M5 4WT, United Kingdom

\begin{abstract}
Within an increasingly busy seascape, competition between different uses of marine resources is growing. Offshore-energy generation in particular is expanding rapidly, with implications for both existing users and nature conservation. Marine spatial planning is seen as the primary tool for mitigating conflicts and optimising resources allocation, and within its processes, effective and timely stakeholder involvement is essential to success. In reality, however, stakeholder involvement in planning is rarely seen as effective, especially from the stakeholders' perspective. Using illustrative examples, I review why stakeholder involvement is so important, what constitutes meaningful participation, and what prevents the successful incorporation of stakeholders into planning processes, examining issues of integration, transparency and communication. I look at how stakeholder engagement in planning process driven by pressure to expand offshore energy can have unique characteristics that need to be accounted for. Finally, I consider ways to make stakeholder participation in planning inclusive, meaningful, and transparent. In particular I describe how participatory mapping can be used to collect quantitative, spatial stakeholder data that can be incorporated into trade-off analysis and optimisation processes.
\end{abstract}




\section{Introduction}

As our oceans get busier, and competition for resource access grows, the need for more effective and integrated management of the marine environment becomes increasingly pressing (Crowder et al., 2006; Douvere et al., 2007). Marine spatial planning is seen as the main tool to resolve conflict between stakeholders, integrate multiple sectors, and rationalise the multifaceted complexities of marine management (Douvere et al., 2007; Ehler and Dourvere, 2009, Chapter 1). Marine spatial planning is inherently a participatory process in which stakeholders play a fundamental role (Ehler \& Douvere, 2009; Calado et al., 2010). The importance of stakeholder participation in marine spatial planning is recognised in international, regional, and national policies (Calado et al.. 2010; Flannery \& Cinnéide, 2008; Commission of the European Community, 2008), and in some places is now required by law (Kerr et al., 2014). Indeed, stakeholders are included to some capacity in almost all marine spatial planning process (Collie et al., 2013); however, the scope and extent of stakeholder involvement differs greatly among countries (Collie et al., 2013), and is often culturally influenced (Elher, personal communication, Ocean Visions Consulting, 2017).

Incorporating stakeholders is important for many reasons, not least because they can enhance the quality of resultant decisions (Reed, 2008; Brody, 2003) and improve the support for marine spatial plans (Pomeroy \& Douvere, 2008). However, the impacts of incorporating stakeholders on the quality of, and the support for, planning outcomes is highly influenced by the process by which those plans were derived (Reed, 2008). Unfortunately, many stakeholders do not feel satisfied with participation processes (Pita et al., 2011; Yates, 2014; Reilly et al., 2016), and many planning endeavours have failed due to poor stakeholder engagement (e.g., Weible, 2008; Anderson, 2013).

Many marine spatial planning process were initiated as a result of expanding offshore energy developments, particularly marine renewables (Jay, 2010, Chapter 1, Chapter 12). The combined effects of rising demands for energy, desires to curtail carbon emissions, and limited development options on land have seen a large rise in offshore wind and an increasing interest in other types of marine renewable energy sources (Jay, 2010; Pelc \& Fujita, 2002). Discovery of new fossil-fuel deposits also opens up the possible expansion of non-renewable offshore-energy extraction (Chapter 14). Offshore energy competes for space with existing, often longstanding uses/stakeholders, and the resultant conflicts have been a substantial 
driver to rationalise management and move to more integrated governance. In this sense, offshore energy is both a driver of, and a stakeholder in, marine spatial planning.

In this chapter I consider why stakeholders should be the heart of marine spatial planning, and I explore the reality of stakeholder participation, which is invariable tricky, costly, often ineffective, and sometimes just fails. Following a discussion on successful incorporation of stakeholders into marine spatial planning, in which I consider the added complexities of offshore energy, I conclude by looking at some of the tools that can be used to enable more effective and transparent stakeholder participation.

\section{Stakeholders at the heart of marine spatial planning}

Marine spatial planning problems are complex, multifaceted, and often contentious. To optimise the allocation of space and meet objectives, which usually span social, economic, and ecological aims, it is essential that as complete an understanding of the planning problem is obtained as possible. To do this, it is fundamental that stakeholders, a vital source of knowledge that can improve both the planning process and the resultant plans, are involved at all stages of marine spatial planning (Commission of the European Community, 2008).

Stakeholders involvement allows planners to appreciate the wider context of a given planning scenario, and targeting a broad range of expert and 'non-expert' input is important to gain as much of the multifaceted nature of this context as is feasible (Fletcher et al., 2013; Middendorf \& Busch, 1997; Reed, 2008). Different stakeholder groups have different priorities (Clarke et al., 2016), and even differ on how they think the marine spatial planning process should be done (Gopnik et al., 2012). Stakeholders are best placed to explain their own priorities and to describe the conflicts they experience with other stakeholders (Yates, 2014), but they can also provide insight into wider social and political values that would not be gained through adopting an exclusively scientific approach (Middendorf \& Busch, 1997). Data gaps are common in marine spatial planning and stakeholders can provide valuable data that might not have otherwise been available, such as the distribution of current use of marine space (Yates \& Schoeman, 2013). These data can then be incorporated into the decisionmaking process, enhancing the planners' ability to find the most efficient planning options (Yates \& Schoeman, 2014). Stakeholders can also identify and develop opportunities, such as co-location (Chapters 10, 11 and13) that might not have occurred to a planner. 
With stakeholders, planners can explore and get a more holistic understanding of the potential impacts of different planning options. It is not only the planner(s) that gain from this improved understanding; different stakeholders can also develop a greater appreciation of each other's needs, prioritises, and aspirations. Seen by some as a learning and iterative procedure that is as important as the final plan, a collaborative stakeholder-centred marine spatial planning process should allow stakeholders to learn about and recognise the legitimacy of each other's viewpoints (Keen \& Mahanty, 2006). Indeed, stakeholders involved in a marine spatial planning pilot study in Dorset (United Kingdom) identified the opportunity to "network with people you wouldn't normal come across" as a key strength of the process, and they attributed their improved knowledge of marine spatial planning and issues to the "broad selection of people involved" (Fletcher et al., 2013).

Being involved in marine spatial planning improves stakeholders' understanding of the complexities involved and provides planners and managers the opportunity to explain the need for change, including any underpinning legislation or policy drivers that influence the planning process (Fletcher et al., 2013). Increased understanding of both the need for management measures and the process by which they developed should lead to greater acceptance and compliance (Innes, 1996). Thus, as well as stakeholders contributing to the planning process, involving them can also been seen as an important capacity-building exercise (Nutters \& Pinto da Silva, 2012; Anderson, 2013).

A stakeholder-centred planning process also increases the perception of ownership and inclusiveness of any resultant plans, which in turn should increase the ease of implementation of the final plan (Cinnéide, 2007). This sense of ownership of the planning process combined with an improved understanding of other viewpoints is thought to lead stakeholders away from competitive-interest bargaining and towards consensus building (Healey, 2006), which in turn should lead to greater support and reduced inter-stakeholder conflict (Flannery \& Cinnéide, 2008). Indeed, some suggest that while the plan is the ultimate goal, it is the participatory process and the increased capacity and support that results from it that is in fact the most valuable outcome ((Flannery \& Cinnéide, 2008).

Stakeholder attitudes and behaviours can influence both positively and negatively the outcome of management endeavours (Alexander et al., 2012; Pita et al., 2011), and evidence 
shows that the flipside of successful engagement is also true - inadequate stakeholder engagement can cause the planning process to fail. Even a small group of disengaged stakeholders can railroad a project; for example, in in South Australia, failure to address the concerns of the community led to the emergence of a small protest group and ultimately, the abandonment of a windfarm development (Anderson, 2013).

Of course, involving stakeholders is not a small or straightforward task; on the contrary, it is inherently complicated, costly, and potentially risky. Bringing different groups of stakeholders together could be the best way to foster greater understanding of the issues and improved appreciation of other viewpoints, but it does mean bringing together a lot of opposing and potentially hostile points of view. Discussing conflict can be a means to resolve it, but these discussions need multiple meetings, substantial time, and careful, experienced facilitation (Reed, 2008). The more inclusive the process and the more stakeholders involved, the more time and monetary costs are likely to be required.

Some argue that stakeholder participation can become 'talking shops' that achieve little and delay decisive action (Bojorquez-Tapia et al., 2004; Vedwan et al., 2008). Good leadership and clear aims for the participation process are important to help avoid this, but it is essential to acknowledge from the beginning that stakeholder participation will take time, cost money, and likely get messy along the way. With this acknowledgement, adequate resources to support stakeholder participation must also be allocated (Degnbol \& Wilson, 2008; Fletcher et al., 2013). Consideration of resource need should extend beyond government departments to include stakeholder groups who will need to allocate sufficient staff and members time to engage fully in the entire planning process (Fletcher et al., 2013).

Stakeholder participation does not take place in a power vacuum (Reed, 2008). Among stakeholders groups, and indeed within a given stakeholder group, there will be those that are, or are perceived to be, more powerful than others, and there will be those that have been previously marginalised. The offshore energy industry is a prime example of a 'powerful' stakeholder with a lot of resources that can seem intimidating to small, coastal communities (Baker et al., 2004). Participation processes, if not carefully organised, can reinforce existing group dynamics and perceptions rather than empowering the marginalised. Careful consideration of equity of representation, as well as equity of impact, has to be made when 
developing participation processes. Finding ways to balance power, and the perception of power, is essential for allowing all stakeholders to contribute. It is also important to recognised that stakeholder groups are themselves heterogeneous and representatives sent to engage in marine spatial planning might also not be truly representative of the stakeholder groups they represent (Yates, 2014). For example, the fishing community, which is arguably the stakeholder group that will be most directly impacted by the expansion of offshore energy, has diverse spatial priorities depending on target species, gear type, boat size, and home port (Yates \& Schoeman, 2013). Participation processes need to enable incorporation of this detail within stakeholder sub-groups to allow as complete as possible a picture of the user-user and user-nature conflicts that need to be addressed during the planning processes.

There is also a need to ensure that stakeholders have the support they need to be able to participate (Fletcher et al., 2013). Marine spatial planning is complicated, and aspects can be highly technical. The credibility of participation processes has in the past been criticised on the basis that stakeholders do not have sufficient expertise to engage meaningfully (e.g., Fischer and Young, 2007). While this might seem a reasonable concern, it does display a certain arrogance of traditional 'expertise' and does not acknowledge that one of the main benefits of the processes is mutually increased understanding of the issues contained within marine spatial planning. Fishers might not understand the intricacies of offshore wind-farm structures, but nor do engineers understand the intricacies of fishing, and neither group is likely to appreciate fully the impact of expanding or contracting their activities on the socioeconomic situation of the wider coastal community. Moreover, traditional science is increasingly recognising that stakeholders, particularly fishers, can greatly contribute to our understanding of the marine environment (Hind, 2012). Marine spatial planning will inevitably require many different types of 'experts', and those experts will need to develop skills to communicate between sectors. Only by bringing stakeholders together will planners be able to start to piece together the complex reality of a planning situation. Arguably, only with all those different expertise's contributing will the most innovative solutions be found.

\section{Meaningful participation}

Marine spatial planning is most commonly led by government agencies, and most processes involve stakeholders; however, participation varies substantially in the methods employed and the amount of stakeholder involvement in decision making (Collie et al., 2013). For 
participation to be meaningful, stakeholders have to have some influence on the outcome of planning ((Flannery \& Cinnéide, 2008). The most meaningful participation will involve stakeholders right from the phase of objective setting (Ehler \& Douvere, 2009). Of course, this does not always happen, and there are many different models that stakeholder participation can follow.

Participation can be divided into five main categories depending on levels of participation ('Participation Spectrum'; International Association of Public Participation 2004; see Figure 1). At the most minimal end of the spectrum, there is one-way communication through information provision. This is a heavily top-down approach, with the government agencies doing the planning and the stakeholders simply being told about it. But the simple provision of information is not meaningful participation. Consultation, a participation method commonly employed by government agencies in Europe, is somewhat more involved, where planners seek stakeholder views about proposed plans. This is still predominantly top-down. Examples include the German Exclusive Economic Zone Plan and Norwegian Barents Sea Plan, where government agencies primarily developed the plan and stakeholders subsequently participated in a public review process (Collie et al., 2013). The extent to which stakeholder views are incorporated in the planning decisions, and the impact consultation has on the final plan, varies greatly. Importantly, while consultation demonstrates a commitment to receive stakeholder feedback, it does not commit to any specific use of that feedback. Whether consultation can constitute meaningful participation will depend greatly on the specifics of the consultation process and the extent to which stakeholder views influence outcomes. It is inevitable, however, that even the most meaningful consultation will be limited in terms of benefits of stakeholder participation, including the extent to which stakeholders feel engaged in the process and the subsequent ownership over the resulting plans. Indeed, experience of consultation with fishers around offshore renewable energy development indicates that consultation is inadequate, with stakeholders going so far as to say it is just a 'box-ticking' exercise (Kerr et al., 2014; Reilly et al., 2016). 
Increasing stakeholder impact on planning decisions

\begin{tabular}{|c|c|c|c|c|c|}
\hline Inform & Consult & \multicolumn{2}{|c|}{ Involve } & Collaborate & Empower \\
\hline $\begin{array}{l}\text { Provide information } \\
\text { to assist stakeholders } \\
\text { in understanding the } \\
\text { planning process, } \\
\text { problems, } \\
\text { opportunities and/or } \\
\text { solutions. } \\
\text { One directional. } \\
\text { No pathway to } \\
\text { impact the decisions. }\end{array}$ & $\begin{array}{l}\text { Provide stakeholders } \\
\text { the opportunity to } \\
\text { feedback on planning } \\
\text { options and/or } \\
\text { decisions. } \\
\text { Stakeholders } \\
\text { concerns and } \\
\text { aspirations listened } \\
\text { to. } \\
\text { Possibly inform } \\
\text { stakeholders how } \\
\text { their input influenced } \\
\text { decisions. }\end{array}$ & \multicolumn{2}{|c|}{$\begin{array}{l}\text { Work directly with } \\
\text { stakeholders } \\
\text { throughout the } \\
\text { process to ensure } \\
\text { that concerns and } \\
\text { aspirations are } \\
\text { constantly } \\
\text { understood and } \\
\text { considered. }\end{array}$} & $\begin{array}{l}\text { Partner with } \\
\text { stakeholders in all } \\
\text { aspects of planning, } \\
\text { including the } \\
\text { development of } \\
\text { alternatives and the } \\
\text { identification of } \\
\text { preferred solutions. } \\
\text { Advice and } \\
\text { recommendations of } \\
\text { stakeholders } \\
\text { incorporated to } \\
\text { maximum extent } \\
\text { possible. }\end{array}$ & $\begin{array}{l}\text { Final decision in the } \\
\text { hands of } \\
\text { stakeholders. }\end{array}$ \\
\hline Relatively rare & \multicolumn{2}{|c|}{ More common in Europe } & \multicolumn{2}{|c|}{$\begin{array}{c}\text { More common in America and } \\
\text { Australia }\end{array}$} & Relatively rare \\
\hline $\begin{array}{l}\text { China, Marine } \\
\text { Functional Zoning } \\
\text { planning process }\end{array}$ & \multicolumn{2}{|c|}{$\begin{array}{c}\text { Norway, Barents Sea Marine Plan } \\
\text { Germany, Exclusive Economic } \\
\text { Zone Plan }\end{array}$} & \multicolumn{2}{|c|}{$\begin{array}{l}\text { USA, California Marine Life } \\
\text { Protection Act } \\
\text { Australia, Great Barrier Reef } \\
\text { Marine Park Zoning Plan }\end{array}$} & $\begin{array}{l}\text { St. Kitts and Nevis } \\
\text { Marine Spatial Plan }\end{array}$ \\
\hline \multicolumn{5}{|l|}{ Top-down } & Bottom-up \\
\hline
\end{tabular}

Figure 1. The spectrum of stakeholder participation, adapted from the International Association for Public Participation core values with marine spatial-planning examples taken from Collie et al. (2013).

At the other end of the scale, there are the bottom-up approaches, where planning starts with maximum stakeholders participation (Figure 1). In these partnerships, participation means that stakeholders are part of setting the agenda and visioning before planning even begins, and the final decision making is normally shared across the partnership. In the California Marine Life Protection Act, for example, stakeholders played active roles in developing goals, synthesising data, assessing impacts, and submitting suggested plans (Weible, 2008; Collie et al., 2013; Gleason et al., 2010). In some cases, participation can go so far as to empower stakeholders with the final decision making, such as in St. Kitts and Nevis, where the stakeholder participants had equal status with the government throughout the planning process (Collie et al., 2013).

Bottom-up approaches should inherently give stakeholders more input to the planning decision, and thus have a much greater opportunity to be meaningful. However, meaningful 
participation also requires that participation is effective. Stakeholders empowered to make planning decisions will need more support, including mediation, facilitation, and technical and scientific expertise. More meaningful participation approaches are inherently more expensive and can take longer, so more funding must be allocated at the outset to ensure the process can continue to completion. Some argue that neither entirely top-down (inform) or bottom-up (empower) approaches can work by themselves, and that a combination should be used (Fleming \& Jones, 2012).

\section{All stakeholders or some}

All individuals, groups and organizations that are in some way affected, involved or interested in marine spatial planning can be considered 'stakeholders' (Pomeroy \& Douvere, 2008). To what extent all of these different stakeholders can and should be incorporated in marine spatial planning is debatable. While stakeholder participation is beneficial, even fundamental to successful marine spatial planning, it is also costly in both time and money. As the number of stakeholders involved increases, it is likely that those costs will also increase. Resources will always be finite, so decisions will have to be made about stakeholder selection. Some stakeholders, such as fishers and offshore energy companies, depend directly on access to the marine environment for their livelihoods. In the case of fishers, their jobs and connection the sea are also central aspects of their social well-being and cultural heritage (Britton, 2012). It has been argued that stakeholders like fishers with direct dependencies and historic connections are more entitled to a role in marine spatial planning, and that stakeholders should be categorised into 'primary', 'secondary', and 'tertiary' in terms of their entitlement to participate (Pomeroy \& Douvere, 2008). Others argue that this 'entitlement' approach makes the process elitist and contradicts the good practice in stakeholder participation developed in terrestrial planning (Ritchie \& Ellis, 2016). Instead, they argue that marine spatial planning should begin from a position where all the views of all stakeholder are central to the process (Ritchie \& Ellis, 2016). This opinion is echoed by others who identify including the wider stakeholder community as a key element of marine spatial planning and the ecosystem approach it embodies (Fleming \& Jones, 2012). Involving all stakeholders also means everyone's concerns can be addressed when they arise, which is generally easier than dealing with them later (Fletcher et al., 2013).

But involving all stakeholders greatly limits the options of how they can participate; there are unavoidable constraints on how many people can fit around a table and have an effective 
discussion, and the more stakeholders there are the fewer the resources available for supporting each individual's participation. Unavoidably, the more inclusive a stakeholder participation process, the less meaningful it can be for each individual.

Methods such as Spatial Access Priority Mapping (Yates \& Schoeman, 2013) and projects such Scotmap (Kafas et al., 2014) enable participation of many individual stakeholder to move from the more traditional consultation following initial planning, to actual involvement in plan development. Nevertheless, even when all opinions are sought, in reality a few individuals will have to be selected to have a more active role in the planning process. For example, in a marine spatial planning project in the Firth of Clyde, Scotland, there was a steering group comprised of a 'core' membership of representatives from marine industries and regulatory bodies in the area, which was complimented with a wider public consultation (Flannery, 2012). This might seem like a sensible approach, but it does means that the core membership was afforded a much more meaningful mode of participation, with a great opportunity to influence the planning process than the general public. That is not necessarily a problem, but it is a choice and should be a conscious, explicit one.

Neither do all stakeholders want everyone else to be involved. For example, some fishers in the United Kingdom consider that the general public should not be involved as stakeholders in marine spatial planning because they believe the general public has limited knowledge of the marine environment and that they are overly influenced by conservation organisations (Fleming \& Jones, 2012; Jones, 2008). However, public involvement as stakeholders is part of many marine spatial planning policies and legislation, including the United Kingdom Marine Bill (The House of Commons, 2009). Thus, mechanisms to enable the wider public to participate in a meaningful and transparent way need to be found, and choices about how the public's contribution is incorporated need to be explicit and openly communicated.

\section{Barriers to meaningful participation}

\section{Integration}

Integrated governance and management of the marine environment is a long-standing international aspiration, identified as an important action within the United Nations Convention of the Law of the Sea (Douvere \& Ehler, 2009), which predates marine spatial planning by several decades (see Chapter 5). Marine spatial planning is now seen as the main 
tool with which to achieve integration (Ehler \& Dourvere, 2009; Crowder et al., 2006; Douvere et al., 2007; Kidd \& Ellis, 2017). But there are many aspects to integration, some of which offer substantial barriers to meaningful stakeholder participation.

First, there is a need to get stakeholders to agree that integrating existing sectoral management is valuable and worth the substantial effort and investment required (Ritchie \& Ellis, 2016). Pre-existing conflict among stakeholders, including government agencies that are reluctant to share power and collaborate with other agencies, can make adopting an integrated approach difficult (Yates et al., 2013; Guentte \& Alder, 2007).

Another issue is lack of relevant knowledge and data, which is one of the most commonly highlighted issues for developing integrated management (Douvere \& Ehler, 2011). Whilst stakeholders represent a huge resource in terms of both data and knowledge, there is an acknowledged need to find robust ways to integrate information from stakeholders with other forms of data (Alexander et al., 2012). For example, there is an expanding literature on the knowledge of fishers and how it should be used to inform marine management (Hind, 2015). However, there are technical and cultural challenges to integrating fisher knowledge, which is often qualitative and generally in non-standard formats that are incongruous with more traditional, highly systematic, and quantitative scientific data. These two types of stakeholders - scientists and fishers - have different expertise and often only limited exposure to each other's expertise. Fisher knowledge can be perceived by scientists to be 'sub-standard' compared to 'real' scientific data, and this attitude can be a substantial barrier to the integration of fishers knowledge (Soto, 2006). Not only is integration of stakeholder information important for filling knowledge gaps, it is also important for legitimacy and stakeholder buy-in. Stakeholders understandably want to see their input used, but failure to integrate relevant data could be used by those dissatisfied with the planning process to try and discredit any decisions as inadequate or incomplete (Collie et al., 2013).

\section{Communication}

Clear, consistent, targeted, and timely communication with stakeholders is fundamental for effective participation and so it must be at the heart of marine spatial planning (Nutters \& Pinto da Silva, 2012; Kannen, 2014). Good communication is essential for establishing and maintaining trust among stakeholders and is central to encouraging collaboration (Dougill et al., 2006). Internal communication within stakeholder groups also needs to be strong, or the 
message and wider engagement can be diluted (Fletcher et al., 2013). Communicating the meaning of participation clearly and the extent to which stakeholder will influence decisions is important to ensuring consistency between expectation and outcomes (Nutters \& Pinto da Silva, 2012). Roles and objectives should be clearly defined to avoid misunderstandings (Portman, 2009). In the case of the Lyme Bay (United Kingdom) planning process, the failure to communicate desired outcomes clearly was considered a major factor in the breakdown of trust (Fleming \& Jones, 2012). Stakeholder also need to understand clearly what is expected from them throughout the process to enable them to provide the desired information, feedback, and input (Portman, 2009).

Communication strategies should also ensure that content is understandable to the target audience (Portman, 2009). This is not just about translating the technical terminology to the lay person, but also communication between different types of technological sectors.

Developing a glossary of terms to facilitate integration of highly specialised knowledge held within different sectors and by different stakeholders is one suggestion for enhancing communication between stakeholder groups (OSPAR Commission, 2009). Communication methods employed should also acknowledge that different stakeholder groups access different sources of information and that diverse communication channels are required, especially if one wishes to encourage more inclusive participation. For example, industrytargeted publications, such as the Fishing News (fishingnew.co.uk), can be an effective way to reach the wider stakeholder group within an industry sector to invite their input. Where possible, exploiting trusted, pre-existing communication channels is advantageous (Fletcher et al., 2013) but by its very nature, marine spatial planning will require the creation of new lines of communication among stakeholders (Nutters \& Pinto da Silva, 2012).

\section{Transparency}

Developing transparency in marine spatial plans is central for ensuring ongoing support and is highlighted in many policy documents and guidelines(Pomeroy \& Douvere, 2008; Gilliland \& Laffoley, 2008; Gopnik et al., 2012), including occurring as one of the 10 key principles in the European Community's Roadmap for marine planning (Commission of the European Community, 2008). Transparency underpins the accountability and legitimacy of both the planning process and the resultant plan (Calado et al., 2010), and increased transparency is one of potential benefits assigned to undertaking marine spatial planning (Ehler, 2008). 
Stakeholders themselves identify a transparent process as an important aspect of success (Gopnik et al., 2012). Transparency is important because it enables both meaningful stakeholder participation and wider public accountability. Stakeholders need to know the 'rules of the game' if they are to engage fully with processes. Transparency is also central to the development and maintenance of trust between stakeholders, which is essential for developing collaborations and for progressing the process in the direction of consensus building (Reed, 2008; Kerr et al., 2014). Some go so far as to suggest that without a transparent process, it is unlikely that stakeholder discussions will lead to a positive outcome (Fleming \& Jones, 2012).

To ensure transparency, stakeholder roles and the decision-making process need to be clear, and resultant decisions need to be communicated and justified to stakeholders (CEC, 2010). Stakeholders need to know in advance what will happen to the information they provide, how it will used, and who will have access to it. For example, fishers report fears that information they share on their most important fishing grounds might be used by competitors or by marine conservation interests as an argument designating marine protected areas (Degnbol and Wilson, 2008, Chapter 15). This issue also arises for offshore energy companies who understandably might be reluctant to share commercially sensitive information if doing so is not protected by some form of confidentially agreement. However, this raises the complexity of designing a transparent process.; If that commercially sensitive information is pertinent to the planning process and could impact a planning decision, then creating enough trust through ensuring confidentiality is important. However, in doing so the ability to be transparent in how a planning decision was achieved is limited.

Thus, two different kinds of transparency have to be managed: internal and external (Degnbol \& Wilson, 2008). Internal ways have to be found for stakeholders to be transparent with each other; however, external transparency, with wider stakeholders and ultimately, the public, requires that all components of marine spatial planning must be accountable. Therefore, internal transparency and/or external transparency must be limited, and careful attention must be paid to balancing the two types (Degnbol \& Wilson, 2008).

\section{Planning with offshore energy might be different}

Many marine spatial planning processes have been driven by the expansion of offshore energy, particularly in Europe (Jay, 2010, Chapter 1), while others have been sparked by a 
desire to enhance marine conservation through the establishment of marine protected areas or marine zoning (Day, 2002; State of Califonia 1999). Reviewing how planning process are different when they involve offshore energy, as a stakeholder and (often) also a driver, compared to processes that do not, is important for considering how to promote meaningful, transparent participation.

One of the main differences is the amount of resources that offshore energy companies have compared to other stakeholders. Their capacity to have dedicated teams to engage in planning usually far exceeds that of other groups of stakeholders. Fishers who wish to participate have to do so at a combined personal loss of (at least) a day's earnings and any associated travel, which can present a substantial barrier to participation, especially when combined with a perception that their participation will not impact anything (Yates, 2014). Even the organizations that represent fishers are becoming overwhelmed by the burden of these new participatory approaches, and thus may eschew involvement even when they feel it is important (Nutters \& Pinto da Silva, 2012).

The other main difference between marine spatial planning processes that include offshore energy (and sometimes designating marine protected area) is that offshore energy is itself a driver of marine spatial planning, as well as a stakeholder within it. As such, offshore energy as a stakeholder might be, or at least perceived to be, in a more powerful position than other stakeholders (Fleming \& Jones, 2012). Offshore energy, particularly renewables, often has an explicit mandate for expansion driven by national and international commitments to reduce greenhouse-gas emissions. Many countries have targets for renewables energy developments (e.g., NI Assembly, 2013) which are generally established at a national level and through processes separate to those for marine spatial planning. Any marine spatial planning with offshore energy will have to take into account these targets, with some inevitability of resource allocation (space) for offshore energy, regardless of objections or conflicts that come up during the planning process. Indeed, there are many examples where marine spatial planning has been initiated because of strategic objectives to expand offshore energy. The main objective of the Bay of Biscay (Spain) Marine Energy Project was allocating an area for developing wave-energy devices (Jones, Qiu and Lieberknecht, 2013). Likewise, the Pentland Firth and Orkney Waters Pilot Regional Marine Spatial Plan (United Kingdom) was driven by an objective to promote wave and tidal energy (Johnson et al., 2016), and promoting oil and gas production drove the Barents Sea Integrated Management Plan in Norway (Olsen et 
al., 2014). In all of these cases, other sectors and objectives were considered, but the main driver was opening up space for the development of offshore energy.

As such, offshore energy starts off on the front foot, knowing that through the process they will gain access; it is how much access and exactly where that still need to be debated. The opposite is true for other stakeholders, like fishers, who know they will lose access to resources and who start out fighting to minimise loss (for more, see Chapter 6). It could be argued that marine spatial planning that aims to meet international commitments under the Convention on Biological Diversity (United Nations, 1992) by designating $10 \%$ of the marine environment under some form of protection presents a similar situation (a pre-existing strategic goal that impacts planning objectives). However, while conservation can be a driver like offshore energy, it is not in itself a 'stakeholder'. Conservation interests can be held by and represented through various stakeholders, but conservation gain (improved ecological integrity and resilience) is a common asset shared across all stakeholders. With marine spatial planning with conservation objectives, there is also far more room for debate and compromise. There can be a requirement to designate $10 \%$ of the area as protected, but what restrictions (if any) there are within those protected areas is not fixed. In contrast, allocation of area for offshore energy excludes other users (although see Chapter 10). As such, marine spatial planning that involves offshore energy, as a stakeholder and a driver, vary from process that do not in three ways: (1) the positions from which stakeholder start, (2) the balance of power, and (3) the options available.

Some argue that experiences to date with marine spatial planning involving offshore energy show that the process is driven by offshore-energy objectives to such an extent that it could be considered 'strategic sectoral planning' (Jones et al., 2016). This concern is echoed by fishers. A fishing industry representative participating in the Lyme Bay planning process in southern England said "... my concern is that they talk about integrated planning, but we are seeing wind farm planning and MCZs [a type of marine protected area] going ahead regardless, so there is not integrated planning. We are seeing the individual industries being planned separately. It is a piecemeal approach of closing areas to mobile gear. We need a more strategic approach" (Fleming \& Jones, 2012). During a planning workshop for the Mull of Kintyre in Scotland, the fishing association representative pointed out "... the negotiations are based upon an assumption that tidal energy would take precedence over other stakeholders" (Chapter 15). 
If achieving strategic offshore-energy objectives is the overriding priority of the process, then trade-offs and compromises for user-user and user-nature conflicts have to align ultimately with those offshore energy objectives, meaning some conflicts will inevitably go unresolved (Jones, Qiu \& Lieberknecht, 2013; Johnson, Kerr \& Side, 2016). In these situations, early stakeholder engagement and meaningful participation is even more important to maximise the possibility of buy-in to a process that will inevitably leave some groups feeling (initially, at least) marginalised. Building trust among stakeholders can help develop collaborations that might lead to innovations, such as co-location (Chapters 10, 11, and 13) that can minimise the impact of the inevitability of resource loss to offshore energy. Transparency about these overarching objectives is essential for developing and maintaining that trust.

\section{Moving forward}

Tools that allow collection of robust stakeholder data from many individual stakeholders can enable more inclusive planning, balance power, and encourage the use of stakeholder data in decision making, especially if the data are collected in a way the facilitates integration with other datasets (Yates \& Schoeman, 2013). Participatory mapping, which had been widely used for gathering local ecological knowledge (see Huntington, 2000), is one way of capturing spatial stakeholder data. To be most effective for marine spatial planning, participatory mapping needs to be quantitative and, in the likely event of only a subset of the stakeholder community making a map, it needs to be scalable to represent the whole community.

Spatial Access Priority Mapping used in Northern Ireland with the fishing community, is one example of a participatory mapping method that can gather quantitative, spatial data from any stakeholder group that can be weighted and scaled to enable the final result to model the entire community (Yates \& Schoeman, 2013). In brief, the method requires the stakeholders to identify all their priority areas, as many and as big as they like, and to indicate any difference in priority between the individual areas. Then their priority is divided over the total area(s) chosen to give each unit area a value to that stakeholder. The resultant maps are intuitive (Figure 2), instantly highlighting areas of high conflict potential if assigned for offshore energy (or any other use that prohibited fishing). Importantly, the method is appropriate across sectors and the data are quantitative, so they can be incorporated into trade-offs, spatial analysis, or into decision support tools like Marxan (marxan.org) or 
Zonation (github.com/cbig) that help to find optimal zoning configurations (Yates et al. 2014; Klein et al., 2008). The method itself is simple and easy to communicate and stakeholders can readily see the impacts of their data on planning outcomes (e.g., Yates and Schoeman, 2014); a similar method was used in Scotland with the fishing community (Kafas et al., 2014). These participatory mapping approaches can require a substantial investment, on the part of both the planning agency and the stakeholders involved, especially if they are aiming for inclusive participation. To realise the potential value of these engagement approaches, there has to be a firm commitment from the outset to include the data, integrating them with other sources, and a transparent pathway to inform decision making.

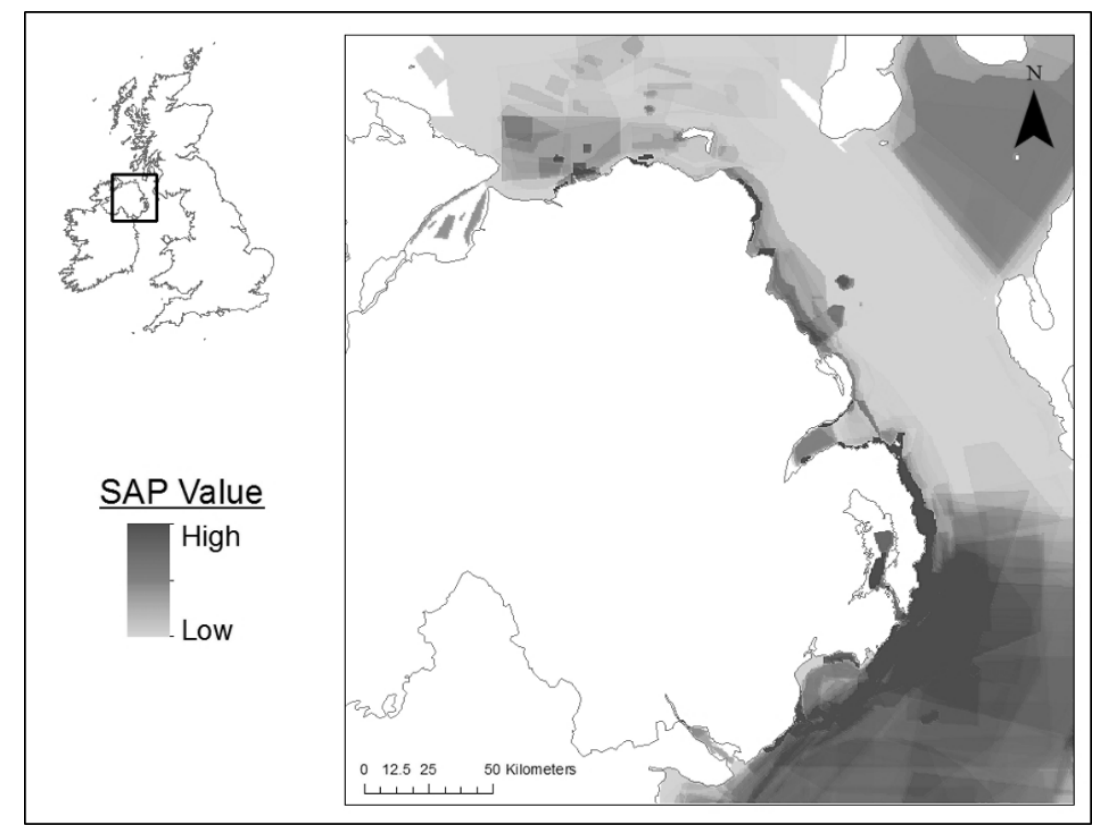

Figure 2. Participatory mapping of stakeholder values (SAP = Spatial Access Priority) to inform marine spatial planning. Maps were made with the Northern Irish fishing community between 2011 and 2012 and provide a quantative, spatial representation of stakeholder priorities. For full details see Yates \& Schoeman (2013).

Decision support tools for spatial planning can be effectively used to show stakeholders the impacts of different planning alternatives, and can be used to facilitate discussions around compromises and trade-offs (Merrifield et al., 2013, Chapter 15). Decision support tools come in many forms, some which might be too technical for wide participation, but there are many others that with some support stakeholders can (and have) used to enable and inform discussions (Stelzenm et al., 2013). For example, Chapter 15 outlines in detail how 'Geodesign' tools were used to facilitate the negotiation of spatial trade-offs around tidalenergy development off the Mull of Kintyre, Scotland. The tools enabled the collection of data from stakeholders, the review of data by them, and then the exploration of possible 
planning solutions based on that data. The development of interactive decision support tools, as well as the ability of stakeholders to submit their own plans for consideration, is credited with the success of the California Marine Life Protection Act planning process (Weible, 2008; Gleason et al., 2010). Most decision support tools are custom-made for a given planning problem (Stelzenm et al., 2013), but there are free, widely applicable options. Functionality will be limited, but there is no reason why some sort of interactive planning tool cannot be made available (with support) for use with stakeholders.

When used effectively, trade-off analysis (Chapter 2) can also increase transparency because it requires clarity in the data, targets, goals, and issues, shows the impacts of different options, and makes the decision-making process more explicit (Collie et al., 2013; Gleason et al. 2010; Yates et al., 2015). Stakeholders can see how different options are weighed against each other and the impact of different choices, so tradeoff analysis can help stakeholders to accept the logic of decisions they may not like from a personal point of view. Trade-off analysis, participatory mapping and spatial optimisation tools (like Marxan and Zonation) can all be used in conjunction to develop and explore the implications of different zoning plans (Yates et al., 2015).

\section{Conclusion}

Ensuring meaningful, effective stakeholder participation in marine spatial planning with offshore energy requires clear communication throughout a transparent process that balances power and ensures integration of stakeholder input. The (real or perceived) notion that offshore energy is at an inherent advantage makes effective engagement with and empowerment of other stakeholders especially important. In this power-imbalance context, it will be even more essential that participation mechanisms clearly show stakeholders how their input has been used if they are to engage in and trust the process. Using methods that allow robust collection of stakeholder data and then integrating those data into trade-off analysis and decisions-support tools, planners create a mechanism for engaging many stakeholders (inclusive) in a meaningful and transparent way. Stakeholders will have the opportunity to inform the processes rather than just be consulted on planning outcomes, and planners can readily communicate the impact stakeholder input had. Practicalities will dictate that only a smaller number of 'entitled' stakeholders will be involved in the more meaningful 
negotiation and decision-making aspects of participation, but this way their decisions will be informed by more inclusive participation. 


\section{Highlights}

- Effective stakeholder participation is essential for successful marine spatial planning

- To be effective, stakeholder participation has to be meaningful with clear pathways to impact decisions

- Offshore energy is a driver as well as stakeholder in marine spatial planning, potentially affording it more power (real or perceived) than other stakeholders

- Participation methods must balance power among stakeholders while clearly acknowledging legislative and policy commitments that may unbalance it

- Tools that allow for transparent collection and incorporation of stakeholder input will ensure more meaningful, robust participation and more defensible decisions 


\section{References}

Alexander, K.A., Janssen, R., Arciniegas, G., O'Higgins, T.G., Eikelboom, T. and Wilding, T.A. (2012). Interactive Marine Spatial Planning : Siting Tidal Energy Arrays around the Mull of Kintyre. PLoS One, 7(1), pp. e30031.

Anderson, C. (2013). The networked minority : How a small group prevailed in a local windfarm conflict. Energy Policy, 58, pp. 97-108. doi: 10.1016/j.enpol.2013.02.048.

Baker, M., Roberts, P. and Shaw, R. (2004). Stakeholder involvement in regional planning. National Report of the Town and Country Planning Association Study supported by the Office of the Deputy Prime Minister. London.

Bojórquez-Tapia, L.A., de la Cueva, H., Díaz, S., Melgarejo, D., Alcantar, G., Solares, M.J., Grobet, G. and Cruz-Bello, G. (2004). Environmental conflicts and nature reserves: redesigning Sierra San Pedro Martir National Park, Mexico. Biological Conservation, 117(2), pp. 111-126.

Britton, E. (2012). The 'having, doing and being'offishing well: assessing the social wellbeing of Northern Ireland's fishing households in a changing coastal environment. Ulster University.

Brody, S.D. (2003). Measuring the Effects of Stakeholder Participation on the Quality of Local Plans Based on the Principles of Collaborative Ecosystem Management. Journal of Planning Education and Research, 22, pp. 407-419.

Calado, H., Ng, K., Johnson, D., Sousa, L., Phillips, M. and Alves, F. (2010). Marine spatial planning : Lessons learned from the Portuguese debate. Marine Policy, 34(6), pp. 13411349.

CEC. (2010). Communication from the commission to the European parliament, the council, the European economic and social committee and the committee of the regions: maritime spatial planning in the EU-achievements and future development COM, vol. 771. 
Cinnéide, M. (2007). Enhancing the development process in Lithuania: towards truly participative governance. In: S. Giguére, ed., Baltic partnerships: integration, growth and local governance in the Baltic Sea Region. Paris: OECD., pp. 83-108.

Clarke, B., Thurstan, R. and Yates, K. (2016). An investigation into the socio - cultural dimension of determining MPA effectiveness, Adelaide, Australia.

Collie, J.S., Beck, M.W., Craig, B., Essington, T.E., Fluharty, D., Rice, J. and Sanchirico, J.N. (2013). Marine spatial planning in practice. Estuarine, Coastal and Shelf Science, 117, pp. 1-11. doi: 10.1016/j.ecss.2012.11.010

Commission of the European Community. (2008). Roadmap for Maritime Spatial Planning : Achieving Common Principles in the EU, COM(2008). [pdf], p. 12., Available at: http://eur-lex.europa.eu/LexUriServ/LexUriServ.do?uri=COM:2008:0791:FIN:EN:PDF.

Crowder, L.B., Osherenko, G., Young, O.R., Airamé, S., Norse, E.A., Baron, N., Day, J.C., Douvere, F., Ehler, C.N., Halpern, B.S. and Langdon, S.J. (2006). Resolving Mismatches in U S Ocean Governance. Science, 313(5787), pp. 617-618.

Day, J.C. (2002). Zoning - lessons from the Great Barrier Reef Marine Park. Ocean \& Coastal Management, 45(2-3), pp. 139-156.

Degnbol, D. and Wilson, D.C. (2008). Spatial planning on the North Sea : A case of crossscale linkages. Marine Policy, 32, pp. 189-200.

Dougill, A.J., Fraser, E.D.G., Holden, J., Hubacek, K., Prell, C., Reed, M.S., Stagl, S. and Stringer, L.C. (2006). Learning from Doing Participatory Rural Research: Lessons from the Peak District National Park. Journal of Agricultural Economics, 57(2), pp. 259-275. doi: 10.1111/j.1477-9552.2006.00051.x.

Douvere, F., Maes, F., Vanhulle, A. and Schrijvers, J. (2007). The role of marine spatial planning in sea use management: The Belgian case. Marine Policy, 31(2), pp. 182-191. doi: 10.1016/j.marpol.2006.07.003 
Douvere, F. and Ehler, C.N. (2009). New perspectives on sea use management: initial findings from European experience with marine spatial planning. Journal of environmental management, 90(1), pp. 77-88. doi: 10.1016/j.jenvman.2008.07.004

Douvere, F. and Ehler, C.N. (2011). The importance of monitoring and evaluation in adaptive maritime spatial planning. Journal of Coastal Conservation, 15, pp. 305-311.

Ehler, C, (2008). Conclusions : Benefits, lessons learned, and future challenges of marine spatial planning. Marine Policy, 32(5), pp. 840-843.

Ehler, C. and Douvere, F. (2009). Marine Spatial Planning - A Step-by-Step Approach. Intergovernmental Oceanographic Commission and Man and the Biosphere Programme. IOC Manual and Guides No. 53, ICAM Dossier No. 6., Paris.

Ehler, C. and Dourvere, F. (2009). Marine Spatial Planning: a step-by-step approach toward ecosystem-based managment, Paris.

Fischer, A. and Young, J.C. (2007). Understanding mental constructs of biodiversity: Implications for biodiversity management and conservation. Biological Conservation, 136(2), pp. 271-282. doi: 10.1016/j.biocon.2006.11.024

Flannery, W. (2012). A roadmap for marine spatial planning: A critical examination of the European Commission' s guiding principles based on their application in the Clyde MSP Pilot Project. Marine Policy, 36(1), pp. 265-271.

Flannery, W. and Cinnéide, M.Ó. (2008). Marine spatial planning from the perspective of a small seaside community in Ireland. Marine Policy, 32(6), pp. 980-987.

Fleming, D.M. and Jones, P.J.S. (2012). Challenges to achieving greater and fairer stakeholder involvement in marine spatial planning as illustrated by the Lyme Bay scallop dredging closure. Marine Policy, 36(2), pp. 370-377. doi: 10.1016/j.marpol.2011.07.006.

Fletcher, S., McKinley, E., Buchan, K.C., Smith, N. and McHugh, K. (2013). Effective practice in marine spatial planning: A participatory evaluation of experience in Southern England. Marine Policy, 39, pp. 341-348. doi: 10.1016/j.marpol.2012.09.003. 
Gilliland, P.M. and Laffoley, D. (2008). Key elements and steps in the process of developing ecosystem-based marine spatial planning. Marine Policy, 32(5), pp. 787-796.

Gleason, M., McCreary, S., Miller-Henson, M., Ugoretz, J., Fox, E., Merrifield, M., McClintock, W., Serpa, P. and Hoffman, K. (2010). Science-based and stakeholderdriven marine protected area network planning: A successful case study from north central California. Ocean \& Coastal Management, 53(2), pp. 52-68. doi: doi.org/10.1016/j.ocecoaman.2009.12.001

Gopnik, M., Fieseler, C., Cantral, L., McClellan, K., Pendleton, L. and Crowder, L. (2012). Coming to the table : Early stakeholder engagement in marine spatial planning. Marine Policy, 36(5), pp. 1139-1149. doi: 10.1016/j.marpol.2012.02.012.

Guentte, S. and Alder, J. (2007). Lessons from Marine Protected Areas and Integrated Ocean Management Initiatives in Canada. Coastal Management, 35, pp. 51-78.

Healey, P. (2006). Collaborative planning : shaping places in fragmented societies. 2 nd ed. Hampshire: Palgrave Macmillan.

Hind, E.J. (2015). knowledge research : a challenge to established fisheries science. ICES Journal of Marine Science, 72, pp. 341-358.

Hind, E.J. (2012). Last of the hunters or the next scientists? Arguments for and against the inclusion of fishers and their knowledge in mainstream fisheries management. The National University of Ireland, Galway.

Olsen, E., Fluharty, D., Hoel, A.H., Hostens, K., Maes, F. and Pecceu, E. (2014). Integration at the Round Table : Marine Spatial Planning in Multi-Stakeholder Settings. PloS one, 9(10), pp. e109964

Huntington, H. (2000). Using traditional ecological knowledge in science: methods and applications. Ecological Applications, 10(5), pp. 1270-1274.

Innes, J.E. (1996). Planning through consensus building: A new view of the comprehensive planning ideal. Journal of the American Planning Association, 62, pp. 460-472. 
Jay, S. (2010). Planners to the rescue : Spatial planning facilitating the development of offshore wind energy. Marine Pollution Bulletin, 60(4), pp. 493-499. doi: 10.1016/j.marpolbul.2009.11.010.

Johnson, K., Kerr, S. and Side, J. (2016). The Pentland Firth and Orkney Waters and Scotland - Planning Europe's Atlantic gateway. Marine Policy, 71, pp. 285-292.

Jones, P., Qiu, W. and Lieberknecht, L. (2013). MESMA Work Package 6 (Governance) Typology of Conflicts in MESMA case studies.

Jones, P.J.S. (2008). Fishing industry and related perspectives on the issues raised by no-take marine protected area proposals. Marine Policy, 32(4), pp. 749-758. Available at: http://linkinghub.elsevier.com/retrieve/pii/S0308597X08000055 [Accessed August 9, 2013].

Jones, P.J.S., Lieberknecht, L.M. and Qiu, W. (2016). Marine spatial planning in reality: Introduction to case studies and discussion of findings. Marine Policy, 71, pp. 256-264.

Kafas, A., McLay, A., Chimienti, M. and Gubbins, M. (2014). ScotMap Inshore Fisheries Mapping in Scotland: Recording Fishermen's use of the Sea. Scottish Marine and Freshwater Science, 5(17), pp. 32. doi: 10.4789/1554-1.

Kannen, A. (2014). Challenges for marine spatial planning in the context of multiple sea uses, policy arenas and actors based on experiences from the German North Sea. Regional Environmental Change, 14(6), pp.2139-2150.

Keen, M. and Mahanty, S. (2006). Learning in sustainable natural resource management: challenges and opportunities in the Pacific. Society and Natural Resources, 19(6), pp. 497-513.

Kerr, S., Watts, L., Colton, J., Conway, F., Hull, A., Johnson, K., Jude, S., Kannen, A., MacDougall, S., McLachlan, C. and Potts, T. (2014). Establishing an agenda for social studies research in marine renewable energy. Energy Policy, 67, pp. 694-702. doi: 10.1016/j.enpol.2013.11.063. 
Kidd, S. and Ellis, G. (2017). From the Land to Sea and Back Again ? Using Terrestrial Planning to Understand the Process of Marine Spatial Planning. Journal of Environmental Policy \& Planning, 14(1), pp. 49-56.

Klein, C.J., Chan, A., Kircher, L., Cundiff, A.J., Gardner, N., Hrovat, Y., Scholz, A., Kendall, B.E. and Airame, S. (2008). Striking a balance between biodiversity conservation and socioeconomic viability in the design of marine protected areas. Conservation biology : the journal of the Society for Conservation Biology, 22(3), pp. 691-700.

Merrifield, M.S., McClintock, W., Burt, C., Fox, E., Serpa, P., Steinback, C. and Gleason, M. (2013). Ocean \& Coastal Management MarineMap : A web-based platform for collaborative marine protected area planning. Ocean \& Coastal Management, 74, pp. $67-76$.

Middendorf, G. and Busch, L. (1997). Inquiry for the public good : Democratic participation in agricultural research. Agriculture and Human Values, 14, pp. 45-57.

NI Assembly, 2013. ELECTRICITY The Renewables Obligation (Amendment) Order (Northern Ireland) 2013, Northern Ireland Assembly.

Nutters, H.M. and Pinto da Silva, P. (2012). Fishery stakeholder engagement and marine spatial planning: Lessons from the Rhode Island Ocean SAMP and the Massachusetts Ocean Management Plan. Ocean \& Coastal Management, 67, pp. 9-18.

Olsen, E., Holen, S., Hoel, A.H., Buhl-Mortensen, L. and Røttingen, I. (2016). How Integrated Ocean governance in the Barents Sea was created by a drive for increased oil production. Marine Policy, 71, pp. 293-300.

OSPAR Commission. (2009). Overview of national spatial planning and control systems relevant to the OSPAR maritime area, no. 444, ISBN:978-1-90684084-6.

Pelc, R. and Fujita, R.M. (2002). Renewable energy from the ocean. Marine Policy, 26, pp. 471-479. 
Pita, C., Pierce, G.J., Theodossiou, I. and Macpherson, K. (2011). An overview of commercial fishers' attitudes towards marine protected areas. Hydrobiologia, 670(1), pp. 289-306.

Pomeroy, R. and Douvere, F. (2008). The engagement of stakeholders in the marine spatial planning process. Marine Policy, 32(5), pp. 816-822.

Portman, Michael. (2009). Involving the public in the impact assessment of offshore renewable energy facilities. Marine Policy, 33(2), pp. 332-338.

Reed, M.S. (2008). Stakeholder participation for environmental management: A literature review. Biological Conservation, 141(10), pp. 2417-2431.

Reilly, K., Hagan, A.M.O. and Dalton, G. (2016). Ocean \& Coastal Management Moving from consultation to participation: A case study of the involvement of fi shermen in decisions relating to marine renewable energy projects on the island of Ireland. Ocean and Coastal Management, 134, pp. 30-40.

Ritchie, H. and Ellis, G. (2016). “ A system that works for the sea "? Exploring Stakeholder Engagement in Marine Spatial Planning. Journal of Environmental Planning and Management, 6, pp. 701-723

Soto, C.G. (2006). Socio-cultural barriers to applying fishers' knowledge in fisheries management: an evaluation of literature cases. Simon Fraser University.

State of Califonia. (1999). Marine Life Protection Act. Fish and Game Code Section 28502863. State of Califonia. USA.

Stelzenmüller, V., Lee, J., South, A., Foden, J. and Rogers, S.I. (2013). Practical tools to support marine spatial planning: A review and some prototype tools. Marine Policy, 38, pp. 214-227.

The House of Commons. (2009). Marine and Coastal Access Bill, London, UK.

United Nations. (1992). Convention on Biological Diversity. Rio de Janiero, Brasil. 
Vedwan, N., Ahmad, S., Miralles-Wilhelm, F., Broad, K., Letson, D. and Podesta, G. (2008). Institutional evolution in Lake Okeechobee Management in Florida: Characteristics, impacts, and limitations. Water Resources Management, 22(6), pp. 699-718.

Weible, C.M. (2008). Caught in a Maelstrom: Implementing California Marine Protected Areas. Coastal Management, 36(4), pp. 350-373.

Yates, K.L. (2014). View from the wheelhouse: Perceptions on marine management from the fishing community and suggestions for improvement. Marine Policy, 48, pp. 39-50.

Yates, K.L., Payo Payo, A. and Schoeman, D.S. (2013). International, regional and national commitments meet local implementation: A case study of marine conservation in Northern Ireland. Marine Policy, 38, pp. 140-150.

Yates, K.L. and Schoeman, D.S. (2014). Incorporating the spatial access priorities of fishers into strategic conservation planning and marine protected area design: reducing cost and increasing transparency. ICES Journal of Marine Science, 72, pp. 587-594

Yates, K.L. and Schoeman, D.S. (2013). Spatial Access Priority Mapping (SAPM) with Fishers: A Quantitative GIS Method for Participatory Planning. PLoS ONE, 8(7), pp. e68424.

Yates, K.L., Schoeman, D.S. and Klein, C.J. (2015). Ocean zoning for conservation, fisheries and marine renewable energy: Assessing trade-offs and co-location opportunities. Journal of Environmental Management, 152, pp. 201-209. 